\title{
To Improvise Risk Reduction Strategies in Obstetrical ICU Admissions
}

\author{
${ }^{1}$ Ripan Bala, ${ }^{2}$ Simran J Kaur, ${ }^{3}$ Madhu Nagpal
}

\begin{abstract}
Background: The goals of management of critically ill obstetric patients involve intensive monitoring and physiological support for patients with life threatening but potentially reversible conditions. Intensive care unit (ICU) is highly specified and sophisticated area of a hospital which is specifically designed, staffed, located, furnished, and equipped, dedicated to the management of critically sick patient, injuries, or complications. The aim of this study is to know the frequency of ICU admissions, to analyze the disease comorbidity related to medical and obstetrical problems, to segregate cause of morbidity, and also to identify and adopt risk reduction strategies.
\end{abstract}

Materials and methods: This observational study was conducted on $35 \mathrm{ICU}$ patients in our institute from 1 December 2016 to 31 May 2018. Our study was divided into two groups. In group I, the intervention was done first followed by ICU intervention and, in group II, ICU stabilization was done prior to surgical intervention. The parameters noted were age, parity, diagnosis on admission, and associated medical and surgical comorbidity; reason for ICU admission, any surgical procedure performed, antenatal, and postnatal admission; details of treatment given like ventilator support, blood and blood components' transfusion, inotropic support, and dialysis. Neonatal outcome was also noted and the total duration was noted. Parameters noted after ICU admissions were cost, duration of stay, patient outcome, review of mortality, and area of improvement.

Results: There were $17.1 \%$ of mortalities observed in our study. The commonest cause for maternal mortality was multiorgan dysfunction (33.3\%) followed by hypertensive disorder of pregnancy $(16.7 \%)$, peripartum cardiomyopathy $(16.7 \%)$, acute fatty liver of pregnancy $(16.7 \%)$, and septic shock $(16.7 \%)$. Severe anemia, cardiac diseases, sepsis, need for a cesarean delivery, and more than one diagnosis on admission are the other risk factors for ICU admission.

Conclusion: The majority of the survivors (69\%) were discharged satisfactorily from the hospital. There is a need for training in emergency obstetrics so that the complication can be managed right at the time of occurrence. There is a need to train obstetricians in obstetric medicine and critical care to do justice to these critically ill pregnant women.

\footnotetext{
${ }^{1}$ Associate Professor, ${ }^{2}$ Junior Resident, ${ }^{3}$ Professor and Head

${ }^{1-3}$ Department of Obstetrics and Gynecology, Sri Guru Ram Das Institute of Medical Sciences \& Research, Amritsar, Punjab, India

Corresponding Author: Ripan Bala, Associate Professor, Department of Obstetrics and Gynecology, Sri Guru Ram Das Institute of Medical Sciences \& Research, Amritsar, Punjab, India, Phone: +91 9417119350, e-mail: ripanchanana@yahoo.co.in
}

Keywords: ICU interventions, Review of mortality, Risk reduction strategies.

How to cite this article: Bala R, Kaur SJ, Nagpal M. To Improvise Risk Reduction Strategies in Obstetrical ICU Admissions. Curr Trends Diagn Treat 2018;2(2):82-87.

\section{Source of support: Nil}

Conflict of interest: None

\section{INTRODUCTION}

Critical illness in pregnancy as a morbidity outcome is difficult to define, hence it should be measured and studied precisely. As stated by Harmer, "Death represents the tip of the morbidity iceberg, the size of which is unknown." ${ }^{\prime \prime}$ The stage at which any condition becomes severe enough to be classified as a critical illness has not been clearly defined. However, it may be helpful to consider critical illness as impending, developing, or established significant organ dysfunction, which may lead to long-term morbidity or death. This allows some flexibility in the characterization of disease severity since it recognizes condition that can deteriorate rather quickly in pregnancy.

It has been suggested that most women suffering a critical illness in pregnancy are likely to be in an intensive care unit (ICU). These cases have been described by some as "near-miss" mortality cases. There are many conditions in pregnancy that occur frequently and require special medical care, but do not actually become critical illness. Most women with these complications have relatively uneventful pregnancies that result in good outcome. Nevertheless, each of these conditions can be associated with significant complications that have the potential for serious morbidity, disability, and mortality.

The successful epidemiological evaluation of any particular disease or condition has several prerequisites. Two of the most important prerequisites are that, first, the condition should be accurately defined and, second, there should be measurable outcomes of interest. Another requirement is that there must be some systematic way of data collection or surveillance that will allow the measurement of the outcomes of interest and associated risk factors.

Historically, surveillance of pregnancy-related critical illness has focused on the well-defined outcome of maternal mortality to identify illness or conditions that might have led to maternal death. Maternal mortality data 
collection is well established in many places, but specific surveillance systems that track severe complications of pregnancy not associated with maternal mortality are rare. Examination of complicating conditions associated with maternal hospitalization can provide information on the types of conditions requiring hospitalized case.

Obstetric patients are generally young and healthy. The goals of management of critically ill obstetric patients involve intensive monitoring and physiological support for patients with life threatening but potentially reversible conditions. It has been suggested that most women suffering from a critical illness in pregnancy are likely to be in an ICU. These cases have been described by some as "near miss" mortality cases. Most women with these complications have relatively uneventful pregnancies that result in good outcome. Nevertheless, each of these conditions can be associated with significant complications that have the potential for serious morbidity, disability, and mortality.

Hemorrhage and pregnancy-related hypertension with its complications are the two common indications for ICU admissions. Studying the near miss cases may help to modify the hospital processes for timely and better obstetric or medical interventions. Establishment of HDU may help in earlier admission of moderately ill patients for better observation and may also reduce ICU admissions. Early assessment and intervention of critically ill obstetrical patients and the provision of separate ICU for them provide an important role but a team approach involving obstetricians and anesthesiologist is ideal. However, our currently available tools and data base for examining these patients still need improvement. $^{2}$

An ICU is a special department of a hospital or healthcare facility that provides intensive care medicine. ICU is highly specified and sophisticated area of a hospital which is specifically designed, staffed, located, furnished, and equipped, dedicated to the management of critically sick patient, injuries, or complications. It is a department with dedicated medical, nursing, and allied staffs (ICU Planning and Designing in India-Guidelines 2010, Guidelines Committee) (ISCCM).

The percentage of obstetric population requiring admission to the ICU is different in different countries based on the socioeconomic status, criteria for ICU admissions, availability of ICU beds, and availability of a high depending unit. It ranges from 0.68 to $0.76 \%$ of deliveries in developed countries. ${ }^{3}$ The same ranges from 0.13 to $4.6 \%$ in developing countries. ${ }^{4}$ The mortality in these patients is high and ranges from 0 to $4.9 \%$ of ICU admissions in developed countries. ${ }^{5}$ The same ranges from 2 to $43.63 \%$ in developing countries. ${ }^{6}$ Hypertensive disorders and obstetric hemorrhage are the two commonest risk factors for ICU admissions. ${ }^{7}$ The other risk factors are sepsis, cardiac disease, and severe anemia. ${ }^{8}$

Since ICU admissions are cost consuming, manpower consuming, and unpredictable result oriented, it is thought provoking to reduce primarily the quantity of risk involved in a suspected severe situation by adopting certain preventive risk reduction interventions so that critical nature of a disease/comorbidity is downstaged.

\section{MATERIALS AND METHODS}

The study was done at the Department of Obstetrics and Gynecology at SGRDIMSR, Amritsar, and the subjects admitted to emergency/out patient department (OPD) or shifted from OT from 1 December 2016 to 31 May 2018.

\section{Inclusion Criteria}

- All the obstetrical emergencies.

- All obstetrical emergencies with/without surgical and medical comorbidities.

- The patients will be evaluated, compared, and categorized into two groups where an intervention is needed as an emergency/urgency to save mother/ fetus/both prior to obstetrical intervention or after the intervention.

\section{Group I}

In which, the delay deteriorated the condition and the severity of the disease becoming fatal to the patient. Such patients after intervention were shifted to critical care unit in a joint approach with anesthesiologist as well as other specialists involved in ICU (intervention preceding ICU admission).

\section{Group II}

Where medical/surgical morbidities required the need of critical care unit to stabilize the patient first, optimal treatment was given for, e.g., cardiac/jaundice/pulmonary dysfunction followed by obstetrical intervention if any (intervention succeeding the optimizing in ICU).

The above two groups were evaluated for their hemodynamic status as well as multiorgan assessment with/ without sepsis.

The parameters noted were age, parity, diagnosis on admission, associated medical and surgical condition, the ward from which the patient was shifted to ICU, reason for ICU admission, any surgical procedure performed, antenatal or postnatal admission, details of treatment given like ventilator support, blood and blood components' transfusion, ionotropic support, and dialysis. The neonatal outcome was noted in terms of death and 
neonatal intensive care admissions. The total duration of ICU stay was noted.

Cost, duration of stay, interventions like blood transfusion, patient outcome by way of long-term and short-term morbidities, and review of mortality in view of dead patients were analyzed.

The patient being referred to coronary care unit (CCU)/ ICU was thoroughly assessed for all the possibilitiescardiac/respiratory/GIT/neurosensorium. The intensive management was supervised by senior obstetricians as well as ICU interventionist. Close follow up of patient for electrolytes/ABG/urinary output was recorded. The need of blood and blood components was analyzed. The sepsis was taken care of in consultation with microbiologist attending ICU.

\section{Statistical Analysis}

The recorded data were compiled and entered in a spreadsheet computer program and analyzed using SPSS version 20 (IBM SPSS Statistics Inc., Chicago, Illinois, USA) Windows software program. Percentages and frequencies were calculated. The statistical test used was Chi-square on three observations on outcome: cause of mortality, outcome of a patients at discharge, and area of improvement.

\section{RESULTS}

The majority of the cases in this study were of 37 to 40 weeks (term) gestation accounting for $37.1 \%$ of cases. About $14.3 \%$ of cases were in the gestational age group of 28 to 34 weeks and $17.1 \%$ of cases were of 35 to 36 weeks. About $8.6 \%$ cases were of 8 to 12 weeks in early pregnancy. About $22.9 \%$ of women were admitted to our hospital in puerperium (Table 1).

About $57.1 \%$ of cases were from rural background and $42.9 \%$ of cases were from urban population. The majority of the cases (74.3\%) were unbooked and only $25.7 \%$ of cases were booked at our hospital. It was further observed that the majority of the cases $(51.4 \%)$ were of poor socioeconomic strata, $25.7 \%$ belonged to lower middle socioeconomic class, and $22.9 \%$ cases belonged to lower class. About $40 \%$ of cases were uneducated, followed by $37.1 \%$ of cases had primary education and $22.9 \%$ of cases had secondary education (Table 2).

The most common procedure was lower segment cesarean section (LSCS) accounting to $48.6 \%$ followed by laprotomy in $14.3 \%$ and $11.4 \%$ underwent cesarean hysterectomy. About $5.7 \%$ of cases had laprotomy for ruptured uterus and ruptured ectopic pregnancy. Normal delivery was done in $2.9 \%$ cases. About $17.1 \%$ of cases were managed conservatively in which intervention was done outside the institute (Table 3).
Table 1: Period of gestation among patients admitted to ICU

\begin{tabular}{lcc}
\hline POG & Number of cases & Percent \\
\hline Puerperium & 8 & 22.9 \\
Up to 12 weeks & 3 & 8.6 \\
Up to 34 weeks & 10 & 14.3 \\
Up to 36 weeks & 6 & 17.1 \\
Up to term & 13 & 37.1 \\
Total & 35 & 100 \\
\hline
\end{tabular}

The most common indication of ICU admissions was postpartum hemorrhage $(n=16)$, hypertensive crisis $(n=7)$, hemodynamic stability $(n=5)$, puerperal sepsis $(n=2)$, asthma $(n=1)$, acute fatty liver of pregnancy $(n=1)$, asthma in the case of placenta accrete $(n=1)$, and tracheostomy management. LSCS was the most common surgical intervention done in our study (Table 4).

The most common ICU intervention was blood transfusion (85.7\%). Mechanical ventilation was done in 14 cases (40\%), inotropic support in 10 cases (10\%), antihypertensives given in 12 cases (34.3\%), anticonvulsants in 9 cases $(25.9 \%)$, and dialysis in $3(8.6 \%)$ cases (Table 5).

It was seen that in two cases, multiorgan dysfunction was the main cause of mortality. One case died due to hypertensive disorder of pregnancy, and acute fatty liver of pregnancy was the cause in other cases. Comparison showed statistically significant results $(p<0.001)$ (Table 6).

Table 7 shows that apart from community awareness which was required in all cases some other areas of improvement were seen. Antenatally, anemia correction,

Table 2: Distribution according to area background, referred or booked, socioeconomic status, and education among the ICU admissions

\begin{tabular}{llrl}
\hline Variables & & No & Percentage \\
\hline Area & Rural & 20 & 57.1 \\
& Urban & 15 & 42.9 \\
Booked/referred & Booked & 9 & 25.7 \\
& Referred & 26 & 74.3 \\
Socio economic & Lower middle & 9 & 25.7 \\
status & & & \\
& Lower & 8 & 22.9 \\
& Poor & 18 & 51.4 \\
Education & Primary & 13 & 37.1 \\
& Secondary & 8 & 22.9 \\
& Uneducated & 14 & 40 \\
\hline
\end{tabular}

Table 3: Distribution procedure done at institute

\begin{tabular}{lcc}
\hline & No. of cases & Percent \\
\hline No procedure & 6 & 17.1 \\
LSCS & 17 & 48.6 \\
Cesarean hysterectomy & 4 & 11.4 \\
Laprotomy & 5 & 14.3 \\
Laprotomy for ruptured uterus & 2 & 5.7 \\
Normal pregnancy & 1 & 2.9 \\
Total & 35 & 100
\end{tabular}


Risk Reduction Strategies

\begin{tabular}{|c|c|c|c|c|}
\hline Indication & Gestational age & Intervention & ICU shifting & No. of cases \\
\hline \multirow[t]{2}{*}{ Eclampsia } & Up to 34 weeks & LSCS & $\mathrm{PPH}$ & 2 \\
\hline & Up to 36 weeks & LSCS & Eclampsia & 4 \\
\hline Preeclampsia & Up to 34 weeks & LSCS & Hypertensive crisis & 3 \\
\hline \multirow[t]{3}{*}{ Placenta praevia } & Up to 28 weeks & Hysterotomy & $\mathrm{PPH}$ & 2 \\
\hline & $\begin{array}{l}\text { Up to } 36 \text { weeks till } \\
\text { term }\end{array}$ & LSCS & $\mathrm{PPH}$ & 5 \\
\hline & Up to 34 weeks & LSCS & Eclampsia & 1 \\
\hline \multirow[t]{3}{*}{ Placenta accreta } & Up to 36 weeks to term & Peripartum hysterectomy & $\mathrm{PPH}$ & 4 \\
\hline & & LSCS & Asthma & 1 \\
\hline & & LSCS & Peripartum cardiomyopathy & 1 \\
\hline Anhydramnios & Up to term & LSCS & $\mathrm{PPH}$ & 1 \\
\hline Acute pancreatitis & Up to term & LSCS & $\mathrm{PPH}$ & 1 \\
\hline Shock & Puerperium & ICU management & Puerperal sepsis & 2 \\
\hline Ruptured uterus & Post abortion & Laprotomy & Hemodynamic instability & 2 \\
\hline Ruptured ectopic & $<12$ weeks & Laprotomy & Hemodynamic instability & 3 \\
\hline Breech & Up to term & LSCS & $\mathrm{PPH}$ & 1 \\
\hline Jaundice & Up to term & NVD & Acute fatty liver of pregnancy & 1 \\
\hline Ludwigs angina & Up to term & LSCS & Tracheostomy & 1 \\
\hline
\end{tabular}

and ultrasound-guided placental localization were the common areas of improvement seen in almost $20 \%$ of cases. Early admission was needed in $17.1 \%$ cases, and blood and blood components' arrangement in $14.3 \%$ of cases. There was a need of institutional delivery and high-risk stratification in $11.4 \%$ of cases and contraception advice in $2.9 \%$ of cases.

\section{DISCUSSION}

Obstetric medicine is unique and complicated. Obstetric medicine is different from the general medicine because

Table 5: Distribution according to ICU interventions

\begin{tabular}{lll}
\hline ICU intervention & No. of cases & Percentage \\
\hline Mechanical ventilator & 14 & 40 \\
Blood products & 30 & 85.7 \\
Inotropes & 10 & 28.6 \\
Dialysis & 3 & 8.6 \\
Anticonvulsants & 9 & 25.9 \\
Antihypertensives & 12 & 34.3 \\
\hline
\end{tabular}

Table 6: Comparison of cause of mortality of cases

\begin{tabular}{|c|c|c|c|c|}
\hline \multirow[b]{3}{*}{ Cause of mortality } & \multicolumn{4}{|c|}{ Survivor/non-survivor } \\
\hline & \multicolumn{2}{|c|}{ Survivor } & \multicolumn{2}{|c|}{ Non-survivor } \\
\hline & $n$ & $\%$ & $\bar{n}$ & $\%$ \\
\hline No mortality & 29 & 0 & 0 & 0 \\
\hline $\begin{array}{l}\text { Hypertensive disorder } \\
\text { of pregnancy }\end{array}$ & 0 & 0 & 1 & 100 \\
\hline $\begin{array}{l}\text { Multiorgan } \\
\text { dysfunction }\end{array}$ & 0 & 0 & 2 & 100 \\
\hline $\begin{array}{l}\text { Peripartum cardio- } \\
\text { myopathy }\end{array}$ & 0 & 0 & 1 & 100 \\
\hline $\begin{array}{l}\text { Acute fatty liver of } \\
\text { pregnancy }\end{array}$ & 0 & 0 & 1 & 100 \\
\hline Septic shock & 0 & 0 & 1 & 100 \\
\hline Count & 29 & 82.9 & 6 & 17.1 \\
\hline
\end{tabular}

of the various physiological changes occurring in pregnancy, and only an experienced obstetrician who has good knowledge of obstetric medicine can interpret and understand complex conditions in pregnancy. The threshold of an insult required for ICU admission is low in obstetric patients compared with that of nonpregnant population. We have seen women developing disseminated intravascular coagulation very rapidly with obstetric complications like hemorrhage and hypertensive disorders. The threshold for ventilator support also is low in pregnancy.

In this study, the rate of ICU admissions conducted from December 2016 to May 2018 at SGRD Amritsar was $1.8 \%$ of all deliveries. A total number of deliveries in this time period were 1,876 in our institute and there were 35 admissions in our ICU.

Al-Suleiman et al. reported a study in 2006 on obstetric admissions to ICU-12-year review with the admission rate of $0.22 \% .{ }^{9}$ Mabie et al. reported the study with the admission rate of $0.9 \%$. The rate in this study is higher than those studies because most of the ICU cases included in this study were booked elsewhere and referred to our institute for tertiary care. ${ }^{10}$

Table 7: Distribution according to area of improvement

\begin{tabular}{lcc}
\hline Area of improvement & No. of cases & Percent \\
\hline No factor & 1 & 2.9 \\
Anemia correction & 7 & 20 \\
Placental localization & 7 & 20 \\
Early admission & 6 & 17.1 \\
High risk stratification & 4 & 11.4 \\
Contraceptive advice & 1 & 2.9 \\
Institutional delivery & 4 & 11.4 \\
Blood arrangement & 5 & 14.3 \\
Total & 35 & 100 \\
\hline
\end{tabular}


Table 8: Area of improvement with respect to infrastructure and human resources

\begin{tabular}{llll}
\hline System & Examples & Yes & No \\
\hline Logistical problems & $\begin{array}{l}\text { Health service- } \\
\text { health service } \\
\text { communication } \\
\text { breakdown } \\
\text { Lack of facilities, } \\
\text { equipment or } \\
\text { consurriables } \\
\text { Lack of blood }\end{array}$ & $\checkmark$ \\
Health personnel & $\begin{array}{l}\text { Lack of human } \\
\text { resources } \\
\text { problems }\end{array}$ & $\checkmark$ \\
& $\begin{array}{l}\text { Lack of anesthetist } \\
\text { Lack of surgeons }\end{array}$ & $\checkmark$ \\
& Lack oxpertises, & $\checkmark$ \\
training or education & $\checkmark$ \\
\hline
\end{tabular}

The commonest age group in our study was between 20 and 30 years (51.4\%) and 11 patients (31.4\%) belonged to the age group of $>30$ years. A study done by Rochat et al. showed that $72 \%$ of cases belonged to the age group of 21 to 30 years. The above results indicate that youth confers protection in critical illness in pregnancy and the adverse outcome of critically ill obstetric patients with advancing age. ${ }^{11}$

The commonest gestational age in our study was term gestation (37-40 weeks) accounting for $37.1 \%$ and $22.9 \%$ in puerperium followed by $17.1 \%$ in the gestational age group of 35 to 36 weeks, $14.3 \%$ in 28 to 34 weeks, and $8.6 \%$ between 8 and 12 weeks indicating that complications are common at term and around the time of delivery. About $22.9 \%$ of puerperal cases which got admitted in our ICU were delivered outside hospitals and were referred here and this could be used as an indicator of care in peripheral hospitals especially in the management of the third stage of labor. Hence, there is a need for education in peripheral hospitals for the nurses and junior doctors in active management of third stage of labor and also to identify at-risk cases and for timely referral. A study done by Rathod et al. had similar results with our study stating a majority of ICU admissions at term followed by puerperium. ${ }^{12}$ Bhadade et al. reported a study which stated that the maximum admissions requiring ICU were in the third trimester (41\%) and in puerperium (33.6\%). ${ }^{13}$

The other demographic features observed showed that $74.3 \%$ of cases were referred and $25.7 \%$ of cases were booked. About $51.4 \%$ of cases belonged to lower socioeconomic strata and $22.9 \%$ of cases belonged to lower middle-class families. A study done by Jain et al. depicted that in referred patients, any delay at an intermediary facility doubled the risk. Subjects belonging to lower socioeconomic class were at almost 2-fold increased risk of admission to ICU as compared to those belonging to middle class. ${ }^{14}$

The most common intervention done during our study was LSCS accounting to $48.6 \%$. Keizer et al. reported a study on obstetric ICU admissions that had a rate of $50.7 \%$ of LSCS as a surgical intervention in ICU patients. ${ }^{15}$ Zwartt et al. reported a study that had a rate of $52.9 \%$ as surgical interventions in ICU patients. ${ }^{16}$ The rate of both the studies is comparable with our study which indicates that most of the women needed operative delivery. Cesarean delivery, especially in the presence of obstetric and medical comorbidities, can be the potential risk factors for ICU admission.

In our study, it was found that blood and blood components' transfusion was the main ICU intervention done in $85.7 \%$ of critically ill patients followed by ventilator support in $40 \%$ of cases. A similar result was reported by Rathod et al. which too described blood and blood components' transfusion as the main mainstay at ICU for intervention. ${ }^{12}$

The number of maternal deaths was 6 which accounts for $14.3 \%$ of obstetric patients admitted in ICU in our study. The commonest causes of maternal mortality were multiorgan dysfunction syndrome $(26.05 \%)$ and each case of septic shock, hypertensive crisis, peripartum cardiomyopathy, and acute fatty liver of pregnancy. Multiorgan dysfunction has been reported as the commonest cause of mortality by Vasquez et al. who reported that the maternal mortality was $11 \%$, with multiple organ dysfunction syndrome (44\%) as the main cause. ${ }^{17}$ Neto et al. also reported that multiorgan failure contributed toward to majority of maternal mortality. ${ }^{18}$ Karnad et al. also reported that irrespective of the primary disease, multiorgan failure commonly occurs in pregnancy as an end result. ${ }^{19}$

The area of improvement in risk reduction strategies in our study with respect to system facility, infrastructure, and human resources is given in Table 8

\section{CONCLUSION}

There is a need for training in emergency obstetrics so that the complication can be managed right at the time of occurrence. Training is also required for the junior doctors working in peripheral health centers in identifying at-risk cases and for timely referral. There is a need to train obstetricians in obstetric medicine and critical care to do justice to these critically ill pregnant women.

\section{REFERENCES}

1. Harmer M. Maternal mortality - is it still relevant? Anaesthesia 1997;52:99-100.

2. Ananth CV. Epidemiology of critical illnesses and outcomes in pregnancy. In: Belfort MA, Dildy GA, Saade GR, et al. ed. Critical Care Obstetrics. 4th ed. Boston: Blackwell Publishing Ltd, 2004; p.11.

3. Sadler LC, Austin DM, Masson VL, et al. Review of contributory factors in maternity admissions to intensive care at a 
New Zealand tertiary hospital. Am J Obstet Gynecol 2013;209:549.e1-e7. doi: 10.1016/j.ajog.2013.07.031.

4. Ibrahim IA, Rayis DA, Alsammani MA, et al. Obstetric and gynecologic admissions to the intensive care unit at Khartoum Hospital, Sudan. Int J Gynecol Obstet 2015;129(1):84. doi: 10.1016/j.ijgo.2014.10.019.

5. Wanderer JP, Leffert LR, Mhyre JM, et al. Epidemiology of obstetric-related ICU admissions in Maryland: 19992008. Crit Care Med 2013;41(8):1844-1852. doi: 10.1097/ CCM.0b013e31828a3e24.

6. Bandeira AR, Rezende CA, Reis ZS, et al. Epidemiologic profile, survival, and maternal prognosis factors among women at an obstetric intensive care unit. Int J Gynaecol Obstet 2014;124(1):63-66. doi: 10.1016/j.ijgo.2013.07.015.

7. Baskett TF, O'Connell CM. Maternal critical care in obstetrics. J Obstet Gynaecol Can 2009;31(3):218-221. doi: 10.1016/ S1701-2163(16)34119-6.

8. Small MJ, James AH, Kershaw T, et al. Near-miss maternal mortality: cardiac dysfunction as the principal cause of obstetric intensive care unit admissions. Obstet Gynecol 2012;119:250-255. doi: 10.1097/AOG.0b013e31824265c7.

9. Al-Suleiman SA, Qutub HO, Rahman J, et al. Obstetric admissions to obstetric ICU-a 12 year review. Arch Gynecol Obstet 2006;274:4. doi: 10.1007/s00404-004-0721-z.

10. Mabie WC, Sibai BM. Treatment in an obstetric intensive care unit. Am J Obstet Gynecol 1990;162:1-4.

11. Rochat RW, Kooniar LM, Atrash HK, et al. Maternal mortality in USA. Obstet Gynecol 1988;72(1):91-97.
12. Rathod AT, Malini KV. Study of obstetric admissions to the intensive care unit of a tertiary care hospital. J Obstet Gynaecol India 2016;66(Suppl 1):12-17. doi: 10.1007/s13224-015-0750-5.

13. Bhadade R, de Souza R, More A, et al. Maternal outcomes in critically ill obstetrics patients: a unique challenge. Indian J Crit Care Med 2012;16:8-16. doi: 10.4103/0972-5229.94416.

14. Jain S, Guleria K, Vaid NB, et al. Predictors and outcome of obstetric admissions to intensive care unit: a comparative study. Indian J Public Health 2016;60:159-163. doi: 10.4103/0019-557X.184575.

15. Keizer JL, Zwart JJ, Meerman RH, et al. Obstetric intensive care admissions: a 12year review in a tertiary care centre. Eur J Obstet Gynecol Reprod Biol 2006;128:152-156. doi: 10.1016/j. ejogrb.2005.12.013.

16. Zwart JJ, Dupuis JR, Richters A, et al. Obstetric intensive care unit admission: a 2year nationwide population-based cohort study. Intensive Care Med 2010;36:256-263. doi: 10.1007/ s00134-009-1707-x.

17. Vasquez DN, Estenssoro E, Canales HS, et al. Clinical characteristics and outcomes of obstetrics patients requiring ICU admission. Chest 2007;131:718-724. doi: 10.1378/chest.06-2388.

18. Neto AFO, Parpinelli MA, Cecatti JG. Factors associated with maternal death in women admitted to an intensive care unit with severe maternal morbidity. Int J Gynaecol Obstet 2009;105(3):252-256. doi: 10.1016/j.ijgo.2009.01.025.

19. Karnad DR, Lapsia V, Krishnan A, et al. Prognostic factors in obstetric patients admitted to an Indian intensive care unit. Crit Care Med 2004;32:1294-1299. 